\title{
BEYOND URBAN PENALTY AND URBAN SPRAWL: BACK TO LIVING CONDITIONS AS THE FOCUS OF URBAN HEALTH
}

\author{
Nicholas Freudenberg, DrPH; Sandro Galea, MD, DrPH; \\ David Vlahov, PhD
}

\begin{abstract}
Researchers have long studied urban health, both to describe the consequences of urban living and to design interventions to promote the health of people living in cities. Two approaches to understanding the impact of cities on health have been dominant, namely, urban health penalty and urban sprawl. The urban penalty approach posits that cities concentrate poor people and expose them to unhealthy physical and social environments. Urban sprawl focuses on the adverse health and environmental effects of urban growth into outlying areas. We propose a model that integrates these approaches and emphasizes urban living conditions as the primary determinant of health. The aim of the model is to move beyond describing the healthrelated characteristics of various urban populations towards identifying opportunities for intervention. Such a shift in framework enables meaningful comparisons that can inform public health activities at the appropriate level and evaluate their effectiveness in improving the health of urban populations. The model is illustrated with two examples from current urban public health practice.
\end{abstract}

KEY WORDS: urban health; social determinants of health; public health interventions.

\section{INTRODUCTION}

Increasingly, the world's ability to meet its health goals will depend on our success in improving the well-being of people living in cities. For the past 200 years, urbanization, the concentration of people and resources in cities, has been a dominant influence on health. By 2007, more than half the world's population will live in cities, and countries in

Nicholas Freudenberg, DrPH, is Distinguished Professor Public Health, Hunter College, City University of New York; Sandro Galea, MD, DrPH, is Associate Director, Center for Urban Epidemiological Studies, New York Academy of Medicine; and David Vlahov, PhD, is Director, Center for Urban Epidemiological Studies, New York Academy of Medicine.

Requests for reprints should be addressed to Nicholas Freudenberg, DrPH, Program in Urban Public Health, Hunter College, City University of New York, 425 East 25th Street, New York, New York 10010; e-mail: nfreuden@hunter.cuny.edu. 
the low-income world are rapidly becoming as urbanized as those of more developed nations. ${ }^{1}$ Global travel and trade have increased exchanges of food, viruses, health practices, and illicit drugs among urban populations. Growing income inequality has contributed to disparities in health among urban populations. The defining characteristics of cities that influence health are population density and diversity, complex social systems, and the many formal and informal organizations that characterize the urban social environment. In this report, we describe current approaches to understanding the impact of cities on health, describe and discuss a model for conceptualizing the disparate influences on the health of urban populations and suggest some ways that such a model can guide research and practice.

Public health researchers have long studied the health of urban populations, both to understand the consequences of urban living and to design interventions and policies to promote health and prevent disease. In the last few decades, research has focused more on individual behavior and access to health care than on the influence of the urban environment itself. Recently, however, the urban setting has again attracted the attention of health researchers. ${ }^{2-5}$ Two approaches to understanding the impact of cities on health have been dominant, namely, urban health penalty and urban sprawl. While both have merit, a deeper understanding of the influence of the urban context on population health requires a more comprehensive framework.

\section{THE “URBAN PENALTY" APPROACH}

The urban health penalty approach grows out of work on the impact of industrialization on the health of urban populations in Europe and the U. S. ${ }^{6-7}$ Its intellectual origins are in the 19th century urban movements for social justice. ${ }^{8}$ This approach posits that cities concentrate poor people, and expose residents to unhealthy environments, leading to a disproportionate burden of poor health. After World War II, the departure of the middle class and jobs to the surrounding suburbs intensified urban poverty and increased racial segregation, ${ }^{9}$ leaving cities with less capacity to meet the needs of increasingly impoverished populations. By the late 20th century, compared to non-urban areas, cities in the U.S. and sometimes in Europe had higher rates of HIV infection, substance abuse, mental illness, infant mortality, asthma, and other conditions. ${ }^{3,10}$ These disparities led to a resurrection of the earlier concept of "urban health penalty". 
The appeal of this concept is that it captures the appalling health conditions that persist in many inner cities, ${ }^{11}$ describes the resulting inequalities in health, ${ }^{12}$ and points to the necessity of reducing racism and improving health conditions in inner cities. However, this approach has its limitations. It tends to equate "urbaness" with class and race, with urban health becoming synonymous with conditions among the minority poor of the inner cities. It under-values the assets of cities, including those of poor neighborhoods, ${ }^{13}$ and inadequately recognizes that cities also affect the health of middle income and wealthy people. The urban penalty does not adequately account for differences in health among lowincome urban neighborhoods, the diffusion of poverty outside cities, the increased diversity of suburbs, or the links within metropolitan regions, all important influences on health.

\section{THE “URBAN SPRAWL” APPROACH}

More recently, the urban sprawl approach has been developed to focus on the consequences of the diffusion of urban populations outside of central cities. Motivated by the rapid suburbanization of U.S. and European cities following World War II, ${ }^{14}$ this approach focuses on the adverse health effects of urban growth into outlying areas. These include increasing automobile pollution and accidents, sedentary life styles, the rise in obesity and diabetes, increased social isolation, and the breakdown of social capital. ${ }^{2}$ Its intellectual foundations are the critiques of uncontrolled urban growth, ${ }^{15}$ the academic focus on metropolitan regions, and the environmentally inspired quest for "sustainable development". ${ }^{16}$ By taking urban health beyond the inner city, this approach correctly identifies a key urban dynamic and raises important policy questions on transportation, energy, and urban planning. ${ }^{2}$ However, this approach also has its limitations. It often overlooks the inner city, neglecting the health of key vulnerable populations. Moreover, by focusing on regional issues, the concept of sprawl can divert attention from the rapidly spreading urban conditions that most directly influence health throughout the world.

The two approaches share some weaknesses. Both focus on a single phenomenon: the concentration and diffusion of populations between central city and its surrounding suburbs, and thus ignore many other important dynamics that influence urban health. Both concentrate on negative aspects of health, and fail to consider the strengths within metropolitan areas. Both are relatively static, describing health within a particular stage of urban development rather than exploring the chang- 
ing processes between and within cities and their surrounding areas. Both were developed in free market industrial nations and their application to newly urbanizing regions or the transitional economies of Eastern Europe are uncertain. In addition, both make a single implicit comparison: the urban penalty approach compares industrialized central cities to wealthier, non-urban areas while the sprawl approach compares urban and ex-urban zones within metropolitan regions. Finally, neither adequately addresses the urban questions of this century, including the impact of globalization, the growing role of markets, and the high rates of income inequality within cities. To guide policies and practices that can improve the health of urban populations, new approaches are needed.

\section{AN ALTERNATIVE APPROACH: FOCUS ON "URBAN LIVING CONDITIONS"}

A more comprehensive framework for urban health should incorporate and integrate the penalty and sprawl concepts as well as consider other features of living in cities that influence health. Building on multilevel ecological models, ${ }^{17}$ such an approach identifies urban living conditions as the principal remediable determinant of individual and community health. Urban living conditions, defined as the totality of daily experiences that characterize urban life, are the primary proximate influence on health. Dimensions of urban living conditions include the physical environment, the social environment, health and social service systems, and the characteristics of urban populations (e.g., behaviors, beliefs, and demographics). Urban life plays out in a variety of settings that interact to influence health: the home, streets, workplaces, transportation systems, neighborhoods, community agencies, health centers, schools, municipal institutions, markets, and the less tangible cultural milieu. The more fundamental determinants of living conditions are social, political and economic factors across global, national and municipal levels. Within each country, enduring social, political, economic, geographic and cultural structures shape how these factors interact.

The health status of any given urban population results from the dynamic interaction of these factors at multiple levels of social organization. A focus on urban living conditions offers a framework for identifying the particular dimensions of urban characteristics that threaten health today and for selecting the most promising strategies for improving these 


\section{FIGURE 1}

A model for the study of urban health

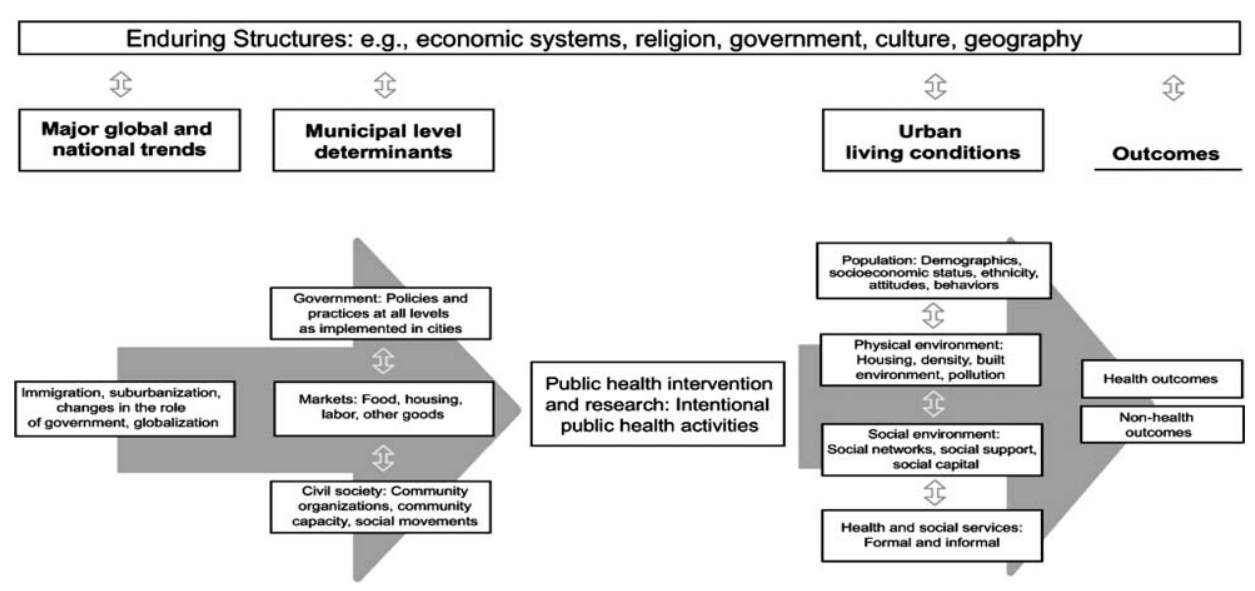

conditions. Some strategies are unique to specific urban settings while others are more general. Figure 1 illustrates this model.

By including macro-level forces in the framework, we avoid the narrow view that individual behavior and lifestyle or, alternatively, neighborhood conditions, are the primary determinants of health. Consistent with the work of 19th century theorists, ${ }^{6,8}$ our model views urban living conditions as the proximate determinants of health. The focus on living conditions allows researchers to study the pathways by which social factors become "embodied" in individuals and populations in a specific time and place and thus affect health. ${ }^{17}$ It also provides a theoretical rationale for linking public health to the urban reform movements that have historically contributed so much to improved urban health., ${ }^{7,19,20}$

Unlike others, who focus on neighborhoods as a primary determinant of health, ${ }^{21}$ we view neighborhoods as one component of many (e.g., household, workplace, municipality, metropolitan region) that comprise the urban living conditions that influence health. Similarly, to avoid the debate between "compositional" (i.e., aggregate population characteristics) and "contextual" (i.e., physical and social environments) effects on health, the model views populations, environments and services as different dimensions of living conditions. The multiple dimensions (or "levels") of the model locate it squarely within the wider recent literature on the social determinants of health and health disparities. ${ }^{22-24}$ However, it expands that literature's focus on socioeconomic class, race, gender, and 
social networks to consider as well urban environments, markets and municipal policies. Including these latter elements may help move the social determinants literature from critique to action since these variables may be more amenable to shorter-term change than the enduring social structures that shape class and race.

\section{ADVANTAGES OF AN INTEGRATED MODEL}

Considering urban health from a comprehensive framework such as the one proposed here has several advantages. First, because the model can be applied both to inner cities (the focus of the urban penalty model) and metropolitan regions (the focus of urban sprawl), it enables researchers to study both and to investigate the interrelationships between the center and the periphery. Viewing a metropolitan region as an urban system that includes both the central city and its surrounding suburb reflects the political, economic and public health literatures that document the strong ties between these areas. ${ }^{25-27}$

Second, the model can be used to study the health of low-income urban populations, to compare the health of different groups within a metropolitan region, or to frame contrasts between urban and non-urban populations. It also allows the focus to be narrowed to specific areas, e.g., a neighborhood, or broadened to more general perspectives, e.g., global cities within the international economy. By proposing a single model that can be adapted to diverse urban situations, we hope to encourage the creation of a unified body of literature on urban health than can guide researchers and practitioners in varied settings.

Third, the model offers public health practitioners more strategic ways to think about interventions. If the primary determinants of the health of urban populations are their living conditions, then the goal of intervention is to bring about health promoting changes in the various dimensions of living conditions. By including changes in the physical and social urban environments as objectives, public health workers can move beyond the narrow focus on individual behavior and health care services that characterize so much of current practice. ${ }^{28,29}$ Similarly, by including more fundamental determinants of living conditions (e.g., municipal policies, market practices, the state of civil society) within their scope, ${ }^{30}$ public health practitioners can design or join interventions that seek changes at these levels. Recent reviews of the health impact of childcare and housing policies and programs illustrate a practical application of developing interventions to improve living conditions. ${ }^{31,32}$ 
A fourth advantage of this approach is that it provides researchers with a focused list of variables that can guide examination of influences on health across levels, systems and outcomes. Thus, it may enable researchers to create a more consistent and interdisciplinary body of literature that can inform research and practice. Moreover, the model includes variables of interest to epidemiologists, clinicians, political scientists, sociologists, anthropologists, geographers, urban planners and architects, to name a few, offering the potential for synthesizing findings across relevant disciplines. Finally, by proposing that cities influence health by exposing their residents to a set of conditions that can be compared in different time frames and places, the model points towards a more unified and useable guide to intervention.

Finally, the model may help to apply the growing list of recommendations for improvement of social conditions related to health (see for example recent reports from Canada, Great Britain and the World Health Organization ${ }^{33-35}$ ) to the specific conditions within urban areas, which often bear the highest burden of illness. One criticism of these reports is that they recommend so many actions that it is difficult to set priorities. Using a model such as the one presented here to organize the epidemiological evidence on the relative burden of disease imposed by various dimensions of the urban environment may help to choose targets for immediate and deferred action.

\section{LIMITATIONS OF MODEL}

The proposed framework clearly has limitations. Like any model, it simplifies a complex reality and risks overlooking the unique dynamics in any particular urban setting. Its broad scope may seem too general for some; so overly comprehensive that it limits utility for testing specific hypotheses. It describes determinants that operate outside as well as within metropolitan areas. Our rationale for labeling it an "urban" model is that it grows out of our practical efforts to describe and improve the health of urban populations and the need to have a unifying framework to organize findings across different urban populations, settings and outcomes. The extent to which this framework is relevant for nonurban areas remains to be determined. Since our goal is to provide an overarching framework to study urban health, the model does not elucidate many important pathways: for example, the impact of urban neighborhoods on health, ${ }^{21}$ developmental or lifespan influences, ${ }^{36}$ the role of culture and ethnic identity, or the influence of changing technology. 
Future research will need to focus more on these sub-themes. Also, the model implicitly suggests that the identified factors are equally important. In fact, different factors may have different importance under different circumstances.

Ultimately, the worth of any model is determined by its utility in understanding a problem, then guiding action for change. We invite others working in urban health to test this model in practice and revise or expand it as needed.

\section{USE OF MODEL TO STUDY URBAN HEALTH}

To illustrate how the model can be used, we provide two examples, one using recent concern about urban deaths from heat waves; the other our own work with drug users. In the first, evidence suggests that deaths, primarily in urban areas, during recent heat waves result from the complex interaction of global, national and local conditions. ${ }^{37-40}$ In a detailed "social autopsy" of the 1995 Chicago heat wave deaths, ${ }^{37}$ Klinenberg examined the role of national factors like the growing trend towards older people living on their own, municipal factors like privatization and cutbacks in social services, and the changing characteristics of the neighborhood social environment that made older people more fearful of leaving their apartment. Klinenberg compared heat wave deaths in Chicago by neighborhood and population and looked at time trends. ${ }^{37}$

By organizing these and other findings in a model such as the one illustrated in Figure 1, it might be possible, for example, to compare the causes and solutions for heat wave deaths in Chicago in 1995 and Paris in $2003 ;^{40,41}$ to consider the combined impact of and interactions among global warming and climate change, urban heat sinks and municipal development policies; ${ }^{2,42,43}$ and to identify an appropriate mix of promising global, national and local strategies to avert heat-related deaths in the future.

In our own work, we have used this model to guide our analysis of intervention strategies to reduce the harm from substance abuse in a low-income neighborhood in New York City. Based on our own research and that of others, we have developed informational campaigns to make it easier for drug users and their community providers to find services, policy initiatives to reduce the barriers to successful reintegration of drug users returning from jail or prison, and capacity building to strengthen the service base in the community. ${ }^{44-47}$ By working to change population characteristics (e.g. knowledge and behavior), health and social service 
delivery, and policies that endanger drug users, we hope to achieve the synergy that multilevel interventions offer. The ecological dimensions of the model have informed our efforts to create horizontal linkages with other local groups working to improve access to housing, health care and employment for people with drug problems and vertical integration with state and national-level researchers and advocacy organizations addressing such issues as harm reduction policies, reentry from prison, and national funding for community research. Obviously, no single group has the capacity or expertise to work at all levels on the full range of determinants of complex problems such as the adverse health consequences of urban substance use. However, the model has helped us to identify how our work fits in with that of others, to make strategic alliances with those working in other sectors or at other levels, and to identify promising opportunities for research and intervention.

\section{CONCLUSION}

The frameworks that guide public health intervention and research inevitably reflect broader social views of cities and their problems. In the 19th and 20th centuries, public health researchers focused on the health consequences of industrialization and urbanization. In recent decades, urban researchers, especially those in the developed world, have emphasized the impact of the diffusion of urban characteristics to wider metropolitan regions. To develop policies and programs that can make healthy cities a reality in both the developed and developing world in the twenty first century, we need to move beyond describing the health-related characteristics of various urban populations and to analyze how living conditions in cities and metropolitan areas affect health, especially differentially between groups within cities. Such a shift in framework is necessary if we are to make meaningful comparisons that can inform interventions at the appropriate level and evaluate their effectiveness in improving the health of urban populations.

\section{ACKNOWLEDGMENTS}

Earlier versions of this report have been presented at the International Society for Urban Health meeting in New York City in October 2003 and the Urbanism and Health Seminar at Columbia University in 


\section{December 2003. We thank the many participants who gave us useful feed- back and suggestions.}

\section{REFERENGES}

1. Population Growth and Urbanization. Population Reports Preview edition June 2001 1-7: Available at www.jhuccp.org/pr/urbanpre.stm

2. Frumkin H. Urban sprawl and public health. Public Health Rep 2002; 117:201-217.

3. American College of Physicians. Inner city health care. Ann Intern Med 1997;127:485-490.

4. Corburn J. Confronting the challenges in reconnecting urban planning and public health. Am J Public Health 2004; 94:541-546.

5. Takano T, ed. Healthy Cities and Urban Policy Research. New York, Routledge, 2003.

6. Chadwick E. Report on the Sanitary Condition of the Labouring Population of Great Britain[1842], ed. MW Flinn, Edinborough: Edinborough University Press, 1965.

7. Rosen G. Preventive Medicine in the United States, 1900-1975: Trends and Interpretations. New York: Science History Publications, 1975.

8. Hamlin C. Public Health and Social Justice in the Age of Chadwick: Britain 1800-1854. Cambridge: Cambridge University Press, 1998.

9. Wilson WJ. When Work Disappears: The World of the New Urban Poor. New York, Knopf: 1996.

10. Vlahov D Galea S. Urbanization, urbanicity, and health. J Urban Health 2002; 79 Suppl 1:S1-S12.

11. McCord C, Freeman HP. Excess mortality in Harlem. N Engl J Med 1990; 322:173-177.

12. Geronimus AT, Bound J, Waidmann TA, et al. Excess mortality among Blacks and Whites in the United States. New Eng J Med 1996; 335:1552-1558.

13. Jacobs J. The Death and Life of Great American Cities. New York: Vintage, 1961.

14. Jackson KT. Crabgrass Frontier: The Suburbanization of the United States. New York: Oxford University Press, 1985.

15. Mumford L. The City in History: Its Origins, Its Transformations and Its Prospects. New York: Harcourt, Brace and World, 1961.

16. Wheeler S. Planning sustainable and livable cities. In RT LeGates and F Stout (Eds). The City Reader. Second Edition. New York: Routledge, 2000, pp 435-445.

17. Kreiger $\mathrm{N}$. Theories for social epidemiology in the 21st century: an ecosocial perspective. Int J Epidemiol 2001; 30:668-677.

18. Freudenberg N, Galea S, Vlahov D. Urban Health: Cities and the Health of the Public. Nashville, TN: Vanderbilt University Press, forthcoming.

19. Rosner D (Ed). Hives of Sickness: Public Health and Epidemics in New York City. New Brunswick, NJ: Rutgers University Press, 1995.

20. Sidel VW, Sidel R (Eds). Reforming Medicine: Lessons of the Last Quarter Century. New York: Pantheon, 1984.

21. Kawachi I, Berkman LF (Eds). Neighborhoods and Health. New York: Oxford University Press, 2003.

22. Black D, Morris JN, Smith C, Townsend P, Whitehead M. Inequalities in Health: The Black Report; The Health Divide. London: Penguin, 1988.

23. Marmot M, Wilkinson R. Social Determinants of Health. Oxford, England: Oxford University Press, 1999.

24. Berkman LF, Kawachi I (Eds). Social Epidemiology. New York: Oxford University Press, 2000.

25. Dreier P, Mollenkopf J, Swanstrom T. Place Matters: Metropolitics for the Twenty-first Century. Lawrence, KS: U of Kansas Press, 2001.

26. Standard and Poor's DRI. U.S. Metro Economies: The Engines of America's Growth. Washington, DC: United States Conference of Mayor's and the National Association of Counties, 1999.

27. Wallace R, Wallace D. The coming crisis of public health in the suburbs. Milbank Memorial Fund Q 1993; 71:543-64.

28. Freudenberg N. Health promotion in the city: a review of current practice and future prospects in the United States. Annu Rev Public Health 2000; 21:473-503.

29. Freudenberg N, Silver D, Carmona JM, Kass D, Lancaster B, Speers M. Health promotion in the city: a structured review of the literature on interventions to prevent heart disease, substance 
abuse, violence and HIV infection in US metropolitan areas, 1980-1995. J Urban Health. 2000; $77: 443-57$.

30. Link BG, Phelan JC. Social conditions as the fundamental causes of disease. J Health and Social Behavior 1995; (extra issue):80-94.

31. Anderson LM, Shinn C, Fullilove MT., et al; Task Force on Community Preventive Services. The effectiveness of early childhood development programs: a systematic review. Am J Prev Med 2003; 24, Suppl 3:32-46.

32. Anderson LM, Charles JS, Fullilove MT, Scrimshaw SC, Fielding JE, Normand J; Task Force on Community Preventive Services. Providing affordable family housing and reducing residential segregation by income: a systematic review. Am J Prev Med 2003; 24, Suppl 3:47-67.

33. Canadian Population Health Initiative. Improving the Health of Canadians. Ottawa, Canada, Canadian Institute for Health Information, 2004. Available at www.cihi.ca.

34. Wilkinson R, Marmot M (Eds). Social Determinants of Health: The Solid Facts. Copenhagen, Denmark: World Health Organization Regional Office for Europe, 1998.

35. Gordon D, Pantaszis C. Tackling inequalities: Where Are We Now and What Can Be Done? London: Policy Press, 2000.

36. Wunsch G, Duchene J, Thiltges E, Salhi M. Socioeconomic differences in mortality: A life course approach. Eur J Popul 1996; 12:167-185.

37. Klinenberg E. Heat Wave: A Social Autopsy of Disaster in Chicago. Chicago: University of Chicago Press, 2002.

38. Weisskopf MG, Anderson HA, Foldy S., et al. Heat wave morbidity and mortality, Milwaukee, Wis, 1999 vs 1995: an improved response? Am J Public Health 2002; 92:830-833.

39. CDC. Heat-related illnesses, deaths, and risk factors-Cincinnati and Dayton, Ohio, 1999, and United States, 1979-1997. MMWR 2000; 49:470-3.

40. Belmin J. The consequences of the heat wave in August 2003 on the mortality of the elderly. The first overview. Presse Med 2003; 32:1591-1594.

41. Tagliabue J. Lack of Air-Conditioning Cited in France's Death Toll. New York Times August 22, 2003, p. A3.

42. Ziska LH, Gebhard DE, Frenz DA, Faulkner S, Singer BD, Straka JG. Cities as harbingers of climate change: common ragweed, urbanization, and public health. J Allergy Clin Immunol 2003; 111:290-295.

43. Kalnay E, Cai M. Impact of urbanization and land-use change on climate. Nature 2003; 423:528531.

44. Galea S, Factor S, Bonner S, et al. Collaboration among community members, local health service providers, and researchers in an urban research center in Harlem, New York City. Public Health Rep 2001; 116:530-539.

45. Van Olphen J, Freudenberg N, Galea S, Ritas C, Palermo AG. Advocating policies to promote community reintegration of drug users leaving jail: first steps in a policy change campaign guided by CBPR. In M Minkler and N Wallerstein (Eds). Community-Based Participatory Research for Health. San Francisco, CA: Jossey-Bass, 2002, pp 371-389.

46. Fuller C, Ahern J, Vadnai L, et al. Impact of increased syringe access: preliminary findings on injection drug user syringe source, disposal, and pharmacy sales in Harlem, New York. $J A m$ Pharm Assoc 2002; 42 Suppl 2:S77-S87.

47. Galea S, Vlahov D. Social determinants and the health of drug users: the role of socio-economic status, homelessness and incarceration. Public Health Rep 2002; 117 Suppl 1:S135-S145. 